\title{
Technical Translation Teaching to the Engineering Students (On the Example of Patent Descriptions)
}

\author{
Ekaterina S. Tarasova \\ National Research Tomsk Polytechnic University, Institute of Power Engineering \\ Email: May.Sky15@gmail.com
}

\section{Doi:10.5901/mjss.2015.v6n3s1p350}

\begin{abstract}
This article considers peculiarities of engineering students teaching to technical documentation translation. Technical translation is viewed as means of the foreign language learning, as the method to improve reading skills and as the efficient technique for the information understanding control. The aim of the following paper is to develop the method of technical translation teaching to the power engineering master's students based on the authentic technical documents. Descriptions of patents were used as the main source of technical information as these documents reflect the latest trends and inventions in the field of study. The research also includes analysis of errors occurring frequently in translation of scientific and technical texts which can lead to mistranslation. Results of the experimental teaching which included pre-experimental test, translation teaching itself and post-experimental test showed the efficiency of the proposed method and proved the necessity of the technical translation course to be integrated in the foreign language training program of engineering students.
\end{abstract}

Keywords: technical documentation translation, engineering students, patents' translation, foreign language teaching, translation errors

\section{Introduction}

The problem of foreign language teaching to the engineering students has attracted much attention of many scientists. However, studies show that the foreign language training is not effective enough, as the modern foreign language professional communication acquired in particular, two new and important characteristics, first of all, it became a real and necessary component of professional development for the majority of graduates, and not for a limited number of them, as it was before. Secondly, it is multicultural, as scientific community includes experts - representatives of other cultures. Hence, there is a need in highly qualified specialists who are able to understand and analyze the professional information in a foreign language.

One of the factors ensuring successful and efficient professional activity of a graduate, is the ability to operate confidently in today's information environment, receive, process and transmit professionally relevant information. The main source of this type of information is an authentic document. Consequently, translation teaching process should include a course of technical translation, which provides a gradual formation of translation skills as a necessary element of a language competence.

A special place among the various information materials is given to patent descriptions, which reflect the current level of science and technology, the trends for development in the future. According to the Federal State Educational Standard of Higher Professional Education of the Russian Federation, master's students should be prepared to provide patent research to ensure non-infringement of new design solutions, their patentability. The study of patents can tell the researcher new and interesting solutions. Therefore, students should know how to translate the patent descriptions.

The aim of the article is to present a theoretically and experimentally proven method of technical documentation translation teaching to engineering students.

Our research has the following objectives:

- to clarify the basic principles, the purpose and describe the content of technical documentation translation teaching in case of non-linguists.

- to develop a set of exercises designed to develop translation skills as a part of the language competence of Master's students with power engineering majors, and test it during a experimental study.

In the following study we consider translation teaching to non-linguists, though there are a plenty of studies in this field (Tarasova, L.V., 2015; Noora, A., 2008, Setati M, Molefe T \& Langa M., 2008).

Issues relating to the content and organization of the course of technical translation, were considered in studies of 
Pumpyansky (1981), Shatilov S.F. (1986), Stulman (1971) et al., However, it should be noted that the issues raised in these studies require further study. Theoretical base for our research was provided by the studies in methods of foreign language writing by Chokwe (2013), Zimnyaya (2012), Musnitskaya (1983), Pumpyanskiy (1997); field specific foreign language teaching in the university by Kitaigorodskaya (1982), Moiseenko (2005); lexical, grammatical and stylistic peculiarities of patent descriptions Klimzo (2003); Tarasova E.S. (2015) the theory of translation teaching in the context of the competence approach by Alekseeva (2004), Wallace (2004).

\section{Methods}

The research was conducted in the National Research Tomsk Polytechnic University, 36 master's students with the major in "Energy, power engineering and electrical engineering" took part in the experimental teaching.

The following methods were used:

- theoretical: study, analysis, synthesis and interpretation of linguistic, psychological, pedagogical and psycholinguistic literature on research; analysis of curricula and textbooks for foreign language training, the analysis of regulations governing the provision of training and professional English translation as a special kind of speech activity;

- empirical: observation, interviews, pre-experimental testing and analysis of experimental teaching, systematization and generalization of experimental data and their interpretation.

Practical experience shows that one of the factors ensuring successful and efficient professional activity of the modern engineer is the ability to operate confidently in today's information environment, receive, process and transmit professionally valuable information, which is the main source of authentic texts in a foreign language. There are many reasons which justify the need in authentic texts translation, but in our opinion the most crucial are the following:

- rapidly developing telecommunication technologies;

- the need in the scientific knowledge exchange;

- awareness of the need in mutual understanding and research;

- the search of the ways and means to solve global problems of professional communication.

Professional training of adult students has certain peculiarities if compared to the training of children. Among these peculiarities we would like to note the following:

- need in education - a student is active and has a clear vision of future plans and career goals;

- explanation (justification), i.e. what is a practical value of the course or module to be studied. The role of a teacher is to show the relevance of the issue or problem raised within the course or module;

- independent character of studying - main feature which distinguishes the behavior and self-consciousness of an adult person. This feature reveals itself in the process of making a choice between available options;

- life experience - in this case master's students are more experienced than undergraduates. This is the reason why a student and a lecturer are equal in the psychological aspect. Students' experience can be used to show real examples for theoretical material;

- practical character of the educational process.

In our study, we considered a group of students aged 20 to 30 years. In psychology the age period from 18 to 25 years is characterized by intensive growth of physical and intellectual abilities, which allows to use more sophisticated methods of teaching and learning. Features of psychological functions of students in this age group involve the systematic use of methods of instruction, based on visual representations, the desire of students to perceive and realize the educational material and organize it as well as to work independently.

Under the term "independent work" we mean any student's learning activity, since it is based on mechanisms of memory, thinking, auditory, visual and vocal apparatus of the student. Thus, the core of independent translation work of students is a productive activity to convert (encode and decode) information and solve creative problems, mastering the technique of independent information search.

\section{Experimental Procedure}

In foreign language learning process, in particular in the course of technical translation, the student is immersed in the active responding process. The student is constantly challenged with differentiation actions: find appropriate equivalents, find synonyms and antonyms, and translate from one language to another. In this case, the value of a foreign language as a subject increases considerably as alongside with the formation of the translation skills students learn scientific or technical style of presenting in Russian as well. They master the style, terminology, certain clichés not only in the foreign, 
but also the native language. All these factors help to train a specialist who can correctly and logically express his or her thoughts both in Russian and English language.

The purpose of this course is to prepare students to implement their professional activities in a foreign language.

Lexical and morphological translation skills are especially important for engineering students. Lexicalmorphological translation skill can be defined as readiness of a student to convert the content of certain lexical units of a Source Language into the Target Language by means of the corresponding language means. This aspect of translation is associated primarily with the development of skills to use the dictionary as the main source of reference in translation, language development guesswork and intuition, the ability to determine the context, and then transfer the content of unfamiliar lexical units in the Russian language.

Technical translation is primarily a tool used for the exchange of scientific and technical information between people, to communicate in different languages. There are different ways of technical text processing, each of them having its own characteristics and its own rules. These forms do not depend on the field of specialization, and so the engineer must be able to perform all kinds of information processing in a foreign language, however, when teaching technical translation it should be noted that the purpose of mastering the art of translation is not the transformation of the student in the professional translator but the formation of certain skills necessary for immediate understanding of foreign text , the ability to interpret the text without translation into their native language with minimal reference to the dictionary.

Translation of scientific and technical documentation is an essential part of the scientific information activities that contributes to overcoming the language barrier. In the translation process the person has the maximum possible understanding of the meaning of the text.

Technical translation course was performed in the Institute of Power Engineering, National Research Tomsk Polytechnic University for master's students. The course includes pre-experimental test, technical translation course for one semester, post-experimental test and. The training was conducted in two experimental groups with different levels of language proficiency: one group with the Upper-Intermediate level of English and another group with Pre-Intermediate Level. As control groups we selected two groups with corresponding levels of English.

Pre-experimental test revealed the difficulties of two basic types: semantic (syntactic, lexical) and normative (related to the violation of the target language norms).

Semantic difficulties occurred since students had not identified correctly semantics of the sentences. An example of such errors is the translation of participles.

Lexical and semantic mistranslations are mostly related to the use of terms in the text. Wrong translation indicates a lack of understanding of the nature of the term and the inability to recognize the term in context. Most often, students take the first meaning which may not be a term.

The second large group of mistranslations - normative errors - is associated with the violation of the rules of the target language, and thus leading to inadequate verbalization in Russian.

To produce a steady flow of unidirectional, or direct current from such a device, it is necessary to provide a means of reversing the current flow outside the generator once during each revolution. - Для производства постоянного электрического потока однонаправленного или постоянного тока в некотором устройстве, необходимо снабжать движущиеся части током снаружи генератора один раз в течение каждого оборота.

In this case, the translation is too literal, furthermore, the meaning was distorted due to a misunderstanding of the syntactic and semantic structure of the sentence. Expression "to provide a means" caused difficulties in almost all translations, where it looked like «снабжать способом», «создать способ», «снабжать средством».

It's worth mentioning that students often confuse conversational and scientific styles. More precisely, they do not even think that they need to follow the rules of any style, in this case the scientific one. Thus, there are stylistic errors. In addition, differences of the scientific styles of Russian and English languages create even greater challenges even for professional translators.

The next step of the experimental procedure was the course of technical translation itself. In the process of technical translation teaching, we were guided by the following criteria for the selection of the material:

1) rational selection of texts that best reflect the style of scientific and technical documentation;

2) texts should not be overloaded with unfamiliar terminology;

3) texts should not be large in size (no more than two printed pages);

4) texts should not be adapted.

Translation skills are being formed gradually while students do the exercises, consisting of both exercises training translation skills (pre-translation exercises), and tasks where students translate texts of a certain volume and within a required period of time. The set of exercises is also characterized by a gradual growth of the complexity level.

Pre-translation exercises are designed to create the conditions for successful implementation of the translation 
process, check the students' language and background knowledge, to show them the solution of typical translation problems.

Pre-translation exercises can be divided into exercises forming general learning skills and those responsible for language skills. A typical example of a pre-translation exercise, forming the language skills, is a paraphrase exercise followed by translation.

Describing the types of exercises included in the course of technical translation teaching, we used the following pre-translation exercises:

1) lexical exercises comprising field-specific terms, names, etc.; search for equivalents of the active vocabulary according to the studied topics;

2) grammatical exercises designed to detect specified grammatical phenomena

3) lexical and grammatical exercises may include exercises to identify discrepancies in the source and target languages, search for equivalents both in English and in Russian. Also, a student is required to find the specified grammatical phenomenon in the text and analyze the method of translation.

Depending on the type and stage of the training, exercises can be performed either in class without preparation or done as homework and then checked in class.

Pre-translation exercises include the tasks aimed at searching for the equivalents, explanation of clichés that may be unknown to the students. The result of the exercise will be that the difficulties of translation (lexical and grammatical, as the purely grammatical phenomena can not be shown without vocabulary) will be removed as students will be using translation transformations. Speaking about translation transformations, we consider the following: reordering, expansion, omission and loan translation. Thus, the exercises include assignments designed to help students to understand the typical phrases and certain syntagmatic units that are "building" material of English scientific writing. It should be mentioned that the lexical and grammatical exercises determine the basis for the subsequent text material. These exercises are aimed at mastering features of scientific and technical documentation on the grammatical and lexical levels. Students will learn how to make up meaningful phrase which is correct from the lexical and grammatical aspects when translating words, expressions and sentences into the target language. Key terms are given in the form of exercises, which excludes the overlearning.

Translation of a coherent text involves the comprehensive use of translation methods and techniques, taking into account the fact that the text is a single unit both semantically and structurally. Training course is divided into two main parts. In the first part of the course students study a new material associated with a specified peculiarity of technical translation, a certain number of lexical and grammatical exercises e.g. examples of translation of terms, phrases and sentences which have certain grammatical forms, etc. Translation teaching material comprises information on the features of the technical texts syntax (grammatically incomplete forms, words indicating sentence structure), the specificity of lexical structures (loan translation, multicomponent terms, translation of neologisms or terms absent in Russian dictionaries ), e.g. exercises for translation of multicomponent terms, among which there are terms that do not subject to the general rule, i.e., the last word is not the main, the translation of neologisms in the field of science and technology:

Translate the following words:

1. Permaculture

2. GTTP

3. ВСЭ

4. cyborg

5. stagflation

6. Katrinagate

7. Spygate

8. Malware

9. Telematics

10. Carboloy

11. Qubit

12. Imagineer

We have also developed exercises for translation of polysemantic terms. It should be noted that these terms are widespread and cause difficulties in translation. Students were given the home assignment task to find all possible meanings of the term, and after that in class they were given various sentences for translation from different fields of science and technology. Such terms include, for example, the word «pattern»:

1. To obtain correct tooth contact pattern two considerations must be observed: One is the lengthwise contact 
pattern that is in the length direction of the teeth, the other is face width pattern that is in height direction of teeth.

2. Eyetracking visualizations show that users often read Web pages in an F-shaped pattern: two horizontal stripes followed by a vertical stripe

3. Design patterns can speed up the development process by providing tested, proven development paradigms.

The second part of the class should begin after the students have sufficiently studied peculiar features of grammar and terminology. Master's students were given small pieces of patent descriptions both in Russian and English languages in "Renewable energy sources". After that the texts were analyzed, interpreted in terms of the lexical and grammatical complexity, similarities and differences in English and Russian versions and translated selectively.

For homework students received patent descriptions and instructions for full or selective translation Moreover students were asked to find mistranslations in the proposed technical documents from the point of view of the adequacy of the translation, e.g. students analyze the article "Solar thermal power station", translated into English from Russian incorrectly in terms of the use of language norms, i.e. lexical and grammatical constructions were "correct" in terms of grammar, but there were a) incorrect in terms of style, b) sounded too "Russian." This exercise helps students get acquainted with the idiomatic structures typical to the English language and absent in the Russian language, as well as develop the ability to see violations of the text style and avoid the use of "Russianisms" and literalism in translation.

The texts also serve as the way to control the extent to which typical syntagmatic units were learnt. As text-based authentic materials we used patent descriptions taken from the Internet (website US Patent Office, the official sites of companies producing equipment).

At the end of semester course of technical translation in all four groups (2 experimental and 2 control groups) we conducted post-experimental test.

According to the test data, the experimental group of masters' students coped more successfully with the task and the growth rate for all criteria in the experimental group was higher than in the control groups. They showed a more confident interpretation of grammatical phenomena, such as the passive voice, modal verbs, infinitive; gave better translations of terminology and vocabulary and considered the style of the original text in translation. It should be noted that these papers had fewer errors related to the literal translation and the use of syntax.

\section{Conclusions}

One of necessary components of the professional language competence is technical translation which is the set knowledge and skills in the field of bilingual communication, determining the perception and interpretation of the text, communicative effect, i.e. the reaction of the recipient to the text.

The need to include the module "Technical Translation" in the discipline "Foreign Language for Master's Students" is stipulated by the following factors: a) when translating field-specific texts students have to search for the language means which are able to express the meaning of the original text in the target language; b) similarities and differences between the mother tongue and foreign language become evident to the students. Consequently these factors assist in training of a specialist who can correctly and logically express the thoughts both in Russian and English.

Developed technique based on the proposed set of exercises was tested during the pilot training. Analysis of the results showed the efficiency of the proposed methods of technical documentation translation teaching to master's students of the technical faculty.

\section{References}

Alekseeva, I. S., (2004). Professional translator training. Moscow: Soyuz.

Chokwe J.M. (2013) Factors Impacting Academic Writing Skills of English Second Language Students. Mediterranean Journal of Social Sciences, Vol. 4. No.14, pp. 377-383.

Kitaigorodskaya G.A. (1982) The methodology of intensive foreign language learning. Moscow: Higher School.

Klimzo B.N.(2003) The art of technical translator. Moscow: R.Valent

Moiseenko Yu.Yu. (2005) The specific character of adult students' teaching // Herald of the Branch of the Kemerovo State University in Anzhero-Sudzhensk. Collected articles/ Edited by N.A. Khamidulina. Tomsk: Tomsk State University Publishing, Issue 4, pp 102 $-104$.

Musnitskaya E. V. (1983) Writing Teaching (Lectures in Methods of Foreign language Teaching). Moscow: Moscow State Pedagogical Institute of Foreign Languages.

Noora, A. (2008). Iranian undergraduate non-English majors' language learning preferences. GEMA Online Journal of Language Studies, 8 (2), 33-44 
Pumpyanskiy A.L.(1981) Introduction to the practice of scientific and technical literature translation into the English language. Moscow. Pumpyanskiy A.L.(1997) Exercises for the translation of English scientific and technical literature from Russian into English. - Minsk: Popurri.

Setati M, Molefe T \& Langa M (2008). Using Language as a Transparent Resource in the Teaching and Learning of Mathematics in a Grade 11 Multilingual Classroom. Pythagoras: Journal of the Association for Mathematics Education of South Africa, 67:14-25.

Shatilov S.F. (1986) The method of the German language teaching in school. Moscow: Prosveschenie, 1986.

Stulman E.A. (1971) Experiment bases in the method of the foreign languages teaching. Voronezh: Voronezh State University Publishing.

Tarasova E.S. \& Kradetskaya A.A. (2015) Peculiarities of Electric Power Engineering Terms Formation. Mediterranean Journal of Social Sciences, Vol. 6. No 2S1, 62-68.

Tarasova L.V. (2015) Intercultural Foreign Language Communication Teaching of 1st Year Students with Non-Linguistic Major Mediterranean Journal of Social Sciences, Vol. 6. No 2S1, 11-17.

The Russian Federation Federal State Standard of the Higher Professional Education for 140100 Field of Training (Power Engineering), Master's Level. [Online] Available: http://www.osu.ru/docs/magistrat/fgos/140400m.pdf (February 3, 2015)

Wallace M.J. (2004) Training Foreign, Language Teachers. A reflective approach. Cambridge: CUP.

Zimnyaya I.A. (2012). Core competencies - the result of a new paradigm of education. [Online] Available: http://aspirant. Rggu /ru /article (September 4, 2014). 